\section{Problems with early and very early intervention in psychosis*}

\author{
RICHARD WARNER
}

\begin{abstract}
Summary 'Early intervention' can refer to two different approaches intervention when the psychosis is already evident and intervention before a psychosis is fully apparent. Each carries a distinctly different set of risks. The hopedfor benefits of early intervention in a fully evident psychosis are based on research that reveals an association between intervention early in the illness and good outcome. Those suffering from a psychosis of recent onset, however, are more likely to experience a spontaneous remission of illness, and this may readily explain the observed association. Early intervention in such cases of good-prognosis psychosis may lead to unnecessary and, sometimes, protracted treatment for those who would do well with no treatment. Intervention in the supposed prodromal phase of psychosis presents more serious hazards. The screening instruments currently available are inadequate for the accurate prediction of psychosis, and the risks of negative effects for the large numbers of people who screen falsepositive are considerable. These risks include unnecessary fear of illness, restriction of life goals, use of medication and their side-effects.
\end{abstract}

Declaration of interest. None.

* Paper presented at theThird International Early Psychosis Conference, Copenhagen, Denmark, September 2002.
Early intervention in psychosis has generated interest and optimism. Health service policy in the UK, Australia, Italy, Canada, and elsewhere has given early intervention a high priority. The enthusiasm, however, is not backed by satisfactory research evidence.

'Early intervention' refers to intervention both before and after the onset of psychosis. The problems, risks and potential benefits are quite different for each of these approaches. I will argue that the expectation of special benefits from early intervention after the onset of illness is premised on weak evidence, and that the approach presents a risk of unnecessary treatment to those who would otherwise experience a brief or mild psychotic disorder. Intervention before psychosis is fully evident is hampered by the lack of adequate screening instruments and interventions and by the danger of negative consequences to those who screen false-positive.

\section{EARLY INTERVENTION AFTER ONSET OF PSYCHOSIS}

The belief that early intervention in psychosis leads to better outcome is based on a misinterpretation of the available data. These data show that the duration of untreated psychosis (DUP) is associated with increased risk of relapse (Crow et al, 1986), psychosocial decline (Jones et al, 1993), prolonged morbidity (Wyatt et al, 1997), increased costs (Moscarelli et al, 1991), worse course and outcome (Helgason, 1990; Haas et al, 1998), and increased duration of the acute episode (Loebel et al, 1992; McGorry et al, 1996). It is unlikely, however, that this association is a direct effect of prolonged psychosis. First episodes of schizophrenia-like conditions progress to remission of psychotic symptoms in $25-50 \%$ of cases in the developed world (World Health Organization, 1979; Ciompi, 1980; Warner, 2004). Samples of patients with a long duration of illness will exclude such good-prognosis cases, but samples with a short duration of psychosis will include patients who recover rapidly. Early detection samples, therefore, are biased to include more good-prognosis cases and will have better overall outcome.

It seems likely that this selection bias explains the association between DUP and poor outcome since the association only holds true for cases of brief duration. Drake et al (2000) note that, in their study, nearly all the association between DUP and outcome is for cases with a duration of 6 months or less and, as shown in Table 1, virtually all the studies that demonstrate an association of DUP with outcome include cases of recent onset, such as schizophreniform disorder. The two exceptions (Waddington et al, 1995; Scully et al, 1997) are studies of the same cohort of long-stay patients admitted to an Irish asylum before the advent of antipsychotic medication in the mid 1950s. The longer the patients were institutionalised prior to the introduction of drug treatment, the worse the outcome. These two studies, then, demonstrate the effect of long-term institutional confinement rather than of untreated psychosis. All the studies that restrict the sample to DSM-IV schizophrenia (with a 6-month duration criterion; American Psychiatric Association, 1994) fail to show an association between DUP and outcome.

Wyatt et al (1997) suggest that untreated psychosis itself may be toxic to brain function. This possibility is rendered unlikely, however, by recent studies that demonstrate a lack of association between DUP and loss of cortical mass, ventricular enlargement or decrements in cognitive functioning (Fannon et al, 2000; Hoff et al, 2000; Norman et al, 2001). Only one study finds DUP to be related to cognitive decline (Joyce et al, 2001).

Claims for the benefits of early intervention, it emerges, go back more than 200 years. 'Throughout the nineteenth century', writes Scull (1979), 'it was an article of faith among those who dealt with lunatics that the deranged were more easily restored in the early stages of the disorder' (p. 111). One private madhouse proprietor, for example, reported, in 1828, that, 'of sixty-nine cases admitted within three months of the first attack, sixty were cured; of seventy cases admitted five months after the onset of the attack, however, only twelve were cured' (Parry-Jones, 1972, 
Table I Studies examining the relationship between duration of untreated psychosis and outcome

\begin{tabular}{ll}
\hline Associated with poor outcome & Not associated with poor outcome \\
\hline Johnstone et al (1986)' & $\begin{array}{l}\text { Linszen et al (1998)' } \\
\text { Makanjuola et al (1987)' }\end{array}$ \\
Helgason (1990)' & Ho et al (2000) \\
Moscarelli et al (1991)' & de Haan et al (2000) \\
Tsoi \& Wong (1991)' & Barnes et al (2000) \\
Loebel et al (1992)' & \\
Waddington et al (1995) & \\
McGorry et al (1996)' & \\
Wyatt et al (1997)' & \\
Scully et al (1997) & \\
Haas et al (1998)' & \\
Carbone et al (1999)' & \\
Larsen et al (2000)' \\
Drake et al (2000)' \\
Browne et al (2000)' \\
\hline
\end{tabular}

I. Includes cases of recent onset (e.g. schizophreniform, psychosis not otherwise specified, etc.).

p. 203). The British Metropolitan Commissioners of Lunacy cited tables 'exhibiting the large proportion of cures effected in cases where patients are admitted within three months of their attacks' (Scull, 1979, p. 112), and the Westminster Review endorsed 'the very great probability of cure in the early stages of insanity' (Scull, 1979, p. 112). The result of this enthusiasm was the passage of the two Lunatics Acts of 1845 which led to the construction of a national network of, sometimes massive, county asylums. We look back, now, with a sense of superiority on the self-promotion of the early asylum proprietors in citing these recovery figures and on the lack of scientific rigour of the politicians in accepting them. We should note, however, that the data currently being offered in support of early intervention suffer from the same weakness as the early asylum tables.

There is danger in overenthusiastic early intervention in those fairly frequent cases of psychosis which progress to early remission without drug treatment. The World Health Organization (WHO) international outcome study demonstrated that $15 \%$ of those presenting with a schizophrenia-like illness in developed world centres recovered completely within 4 months and stayed well for 2 years (World Health Organization, 1979). The Soteria projects in California (Mosher, 1995) and in Berne (Ciompi et al, 1992) and Lehtinen's multicentre study in Finland (Lehtinen et al, 2000) demonstrated that medication use is not essential for good outcome in the first episode of schizophrenia-like illness. Treating such patients with medication at the earliest appearance of symptoms, without thought for the expected outcome, may lock the person experiencing a brief psychosis into a long-term career as a psychiatric patient.

There is also a risk that attempts to increase community recognition of mild and early psychosis may result in people being referred for psychiatric care who would not otherwise have been treated and who may not need it. A comparison of general population incidence surveys of schizophrenia and treatment-contact-based studies suggests that many, perhaps most, people with a psychotic disorder never receive treatment. The mean annual agecorrected incidence of schizophrenia based on an analysis of available service-contact incidence studies is 0.24 per 1000 population with a range of $0.07-0.52$ per 1000 (Warner \& de Girolamo, 1995). The mean incidence of schizophrenia in the five US cities of the Epidemiologic Catchment Area (ECA) community survey, however, is eight times greater, at 2.0 per 1000 (range, 1.0 7.1 per 1000) (Tien \& Eaton, 1992). Even after applying a correction for false-positive and false-negative diagnoses in the survey, based on psychiatrist interviews conducted on a portion of the Baltimore sample (Anthony et al, 1985), the mean incidence of schizophrenia is still six times greater in the ECA study, at 1.5 per 1000 . Similarly, the age-corrected incidence of schizophrenia in the community survey conducted in Lundby, Sweden, by Hagnell et al (1990) is substantially higher, at 3.8 per 1000 , than the mean age-corrected incidence in other Scandinavian studies - 0.16 per 1000, range $0.07-0.24$ per 1000 (Warner \& de Girolamo, 1995). It is by no means clear that broadening the net of detection and treatment will bring benefits to the milder cases of psychosis that currently go unrecognised. This is especially so in the light of the concern that treatment of good-prognosis psychosis with antipsychotic medication may worsen the course of the condition due to the risk of symptom rebound on drug withdrawal (Warner, 2004).

\section{INTERVENTION BEFORE ONSET OF PSYCHOSIS}

McGorry and colleagues in the Personal Assistance and Crisis Evaluation (PACE) clinic report that the most recent version of their screening instrument is capable of $80 \%$ accuracy in predicting which psychiatric clinic patients will develop schizophrenia (Yung et al, 2002). For a number of reasons this instrument, like others (Warner, 2002), is unlikely to be successful in identifying those at imminent risk of psychosis in routine use. In the first place, the $80 \%$ positive predictive value (PPV) for the PACE instrument was achieved by means of a post hoc selection of scale items. For statistical reasons, a measure defined in this way will usually be less successful when applied to a new sample. But, even with this level of accuracy, it will be less predictive in broader populations.

In the PACE sample, $35 \%$ developed a psychosis within 1 year - a much higher rate of transition than would be encountered in most adolescent psychiatric clinics. Bayes probability theorem (Everitt, 1999) tells us that the predictive capacity of a screening instrument is determined by three elements: (a) its sensitivity (in the PACE trial, 0.58); (b) its specificity (0.93); and (c) the base rate of the illness (in the PACE sample, 35\%) (Yung et al, 2002). Applying Bayes' theorem, we find that if used to screen a general population sample with a base rate of $1 \%$, the PACE measure would be correct only $7 \%$ of the time - clearly not a viable basis for intervention. If it were applied to a clinical population where the risk of developing psychosis in a year was, say, $5 \%$, the instrument would be correct only 
$30 \%$ of the time. A false-positive rate of $70 \%$ seems unrealistic for intervening with either medication or cognitive therapy. This problem of the PPV being influenced by the base rate of illness in the tested population may explain why the PACE instrument only achieved a 9\% accuracy when used in another Australian clinic (Carr et al, 2000).

There are other problems with the PACE screening method. The PACE measure, which selects those with quasipsychotic symptoms, transient psychotic symptoms or decline in functioning, is selecting people who are already on the brink of psychosis. In one study, an extraordinary $40 \%$ of PACE participants developed a psychosis within 6 months, many within the first month (Yung et al, 1998). If the sample subjected to preventive intervention is so highly selected that many are within weeks of frank psychosis, how representative is it of the usual clinical population or the whole at-risk group? The possibility of having a significant impact on the occurrence of illness in the general population becomes diminishingly small the more select the cohort being screened.

McGorry and colleagues speculate that a variety of interventions may be effective in preventing the onset of schizophrenia in high-risk cases (McGorry \& Jackson, 1999). The suggested approaches include antipsychotic medication, social skills training, problem-solving techniques, family intervention, 'lifestyle restructure', and training in coping skills. Given the expected number of false-positives, the potential for harm is significant. Should we prescribe antipsychotic medication for someone with no positive symptoms? How much harm will be done to people who will never develop the illness to tell them they are at-risk for schizophrenia, need treatment and must adjust their life goals? (Goode, 1999).

In a pre-illness treatment study conducted by PACE (McGorry et al, 2002), 31 participants were assigned to preventive treatment with low-dose risperidone and cognitive-behavioural therapy, and 28 were assigned to supportive psychotherapy. Only 3 out of 31 in the preventive treatment group developed psychosis after 6 months compared with 10 out of the 28 in the control group. Thus, the onset of psychosis may have been delayed in about 7 of the experimental group. We have to set this positive outcome against some negative aspects: (a) 3 patients took risperidone without benefit; and (b) 21 patients were told they were at-risk for schizophrenia, when they were not, and took risperidone unnecessarily. How does one decide, moreover, how long the 28 symptom-free patients taking risperidone should continue on medication? For threequarters of the group the medication is unnecessary, but one does not know which those are.

Prevention specialists ask a series of questions to determine if a screening programme will do more harm than good (Jablensky, 2000). Does the burden of disease warrant screening? Is there an effective preventive intervention? Is there a good screening test? Will the programme reach those who would benefit? Can the healthcare system handle the screening? Will the screen-positive individuals comply with the proposed intervention? In the case of schizophrenia, the answer to the first question is a resounding 'Yes', but to the remainder the answers are 'No' or, at best, 'Doubtfully'. Looked at in this light, it does not appear likely that pre-illness screening for schizophrenia is likely to be successful.

\section{CONCLUSION}

Intervention before the onset of psychosis appears hazardous, and early intervention after the illness is evident is unlikely to yield the hoped-for benefits.

\section{REFERENCES}

American Psychiatric Association (1994) Diagnostic and Statistical Manual of Mental Disorders (4th edn) (DSM-IV). Washington, DC: APA.

Anthony, J. O., Folstein, M., Romanoski, A. J. et al (1985) Comparison of the lay diagnostic interview schedule and a standardized psychiatric diagnosis: Experience in Eastern Baltimore. Archives of General Psychiatry, 42, 667-675.

Barnes, T. R. E., Hutton, S. B., Chapman, M. J., et a (2000) West London first-episode study of schizophrenia: Clinical correlates of duration of untreated psychosis. British Journal of Psychiatry, 177, 207-211.

Browne, S., Clarke, M., Gervin, M., et al (2000) Determinants of quality of life at first presentation for schizophrenia. British Journal of Psychiatry, 176, 173-176.

Carbone, S., Harrigan, S., McGorry, P. D., et al (1999) Duration of untreated psychosis and I2-month outcome in first-episode psychosis: The impact of treatment approach. Acta Psychiatrica Scandinavica, 100, 96-104.

Carr, V., Halpin, S., Lau, N., et al (2000) A risk factor screening and assessment protocol for schizophrenia and related psychosis. Australian and New Zealand journal of Psychiatry, 34 (suppl.), sl70-sl80.

Ciompi, L. (1980) Catamnestic long-term study on the course of life and aging of schizophrenics. Schizophrenia Bulletin, 6, 606-618.
Ciompi, L., Dauwalder, H.-P., Maier, C., et al (1992) The pilot project "Soteria Berne". Clinical experiences and results. British Journal of Psychiatry, I6I (suppl. 18), 145-153.

Craig, T. J., Bromet, E. J., Fennig, S., et al (2000) s there an association between duration of untreated psychosis and 24-month clinical outcome in a firstadmission series? American Journal of Psychiatry, I57, 60-66.

Crow, T. J., Mac Millan, J. F., Johnson, A. L., et a (1986) A randomised controlled trial of prophylactic neuroleptic treatment. British Journal of Psychiatry, 148 120-127.

de Haan, L., van der Gaag, M. \& Wolthaus, J. (2000) Duration of untreated psychosis and the long-term course of schizophrenia. European Psychiatry, 15 264-267.

Drake, R. J., Haley, C. J., Akhtar, S., et al (2000) Causes and consequences of duration of untreated psychosis in schizophrenia. British Journal of Psychiatry, 177, $511-515$

Everitt, B. S. (1999) Chance Rules: An Informal Guide to Probability, Risk, and Statistics. New York: Copernicus, Springer.

Fannon, D., Chitnis, X., Doku, V., et al (2000) Features of structural brain abnormality detected in first-episode psychosis. American Journal of Psychiatry, 157. 1829-1834.

Goode, E. (1999) Doctors try a bold move against schizophrenia. In New York Times (pp. DI \& D6). New York.

Haas, G. L., Garrett, L. S. \& Sweeney, J. A. (1998) Delay to first antipsychotic medication in schizophrenia: Impact on symptomatology and clinical course of illness. Journal of Psychiatric Research, 32, 151-159.

Hagnell, O., Essen-Moller, E., Lanke, J., et al (1990) The Incidence of Schizophrenia Over a Quarter of a Century. The Lundby Longitudinal Study of Mental Illnesses in a Total Population Based on 42,000 Observation Years. Stockholm: Almquist \& Wiksell.

Helgason, L. (1990) Twenty years' follow-up of first psychiatric presentation for schizophrenia: What could have been prevented? Acta Psychiatrica Scandinavica, 8I 231-235.

Ho, B-C., Andreasen, N. C., Flaum, M., et al (2000) Untreated initial psychosis: Its relation to quality of life and symptom remission in first-episode schizophrenia. American Journal of Psychiatry, 157, 808-815.

Hoff, A. L., Sakuma, M., Razi, K., et al (2000) Lack of association between duration of untreated illness and severity of cognitive and structural brain deficits at the first episode of schizophrenia. American Journal of Psychiatry, 157, 1824-1828.

Jablensky, A. (2000) Prevalence and incidence of schizophrenia spectrum disorders: Implications for prevention. Australian and New Zealand Journal of Psychiatry, 34 (suppl.), s26-s34.

Johnstone, E. C., Crow, T. J., Johnson, A. L., et al (1986) The Northwick Park study of first episodes of schizophrenia. I. Presentation of the illness and problems relating to admission. British Journal of Psychiatry, $\mathbf{1 4 8}$ 115-120.

ones, P. B., Bebbington, P., Foerster, A., et al (1993) Premorbid social underachievement in schizophrenia: Results of the Camberwell Collaborative Psychosis Study. British Journal of Psychiatry, 162, 65-71.

Joyce, E., Hutton, S., Mutsatsa, S., et al (2001) Executive dysfunction in first-episode schizophrenia and relationship to duration of untreated psychosis: the West 
London Study. British Journal of Psychiatry, I8I (suppl. 43), s38-s44.

Larsen, T. K., Moe, L. C., Vibe-Hansen, L., et o (2000) Premorbid functioning versus duration of untreated psychosis in I-year outcome in first-episode psychosis. Schizophrenia Research, 45, I-9.

Lehtinen,V., Aaltonen, J., Koffert, T., et al (2000) Twoyear outcome in first-episode psychosis treated according to an integrated model. Is immediate neuroleptisation needed? European Psychiatry, 15, 313-320.

Linszen, D., Lenior, M., de Haan, L., et al (1998) Early intervention, untreated psychosis and the course of early schizophrenia. British Journal of Psychiatry, $\mathbf{1 7 2}$ (suppl. 33), 84-89.

Loebel, A. D., Lieberman, J. A., Alvir, J. M. J., et al (1992) Duration of psychosis and outcome in firstepisode schizophrenia. American Journal of Psychiatry, 149, II83-1188

Makanjuola, R. O. \& Adedapo, S. A. (1987) The DSM-III concepts of schizophrenic disorder and schizophreniform disorder. A clinical and prognostic evaluation. British Journal of Psychiatry, 15I, 611-618.

McGorry, P. D. \& Jackson, H. J. (1999) The Recognition and Management of Early Psychosis: A Preventive Approach. Cambridge: Cambridge University Press.

McGorry, P. D., Edwards, J., Mihalopoulos, C., et al (1996) EPPIC: An evolving system of early detection and optimal management. Schizophrenia Bulletin, 22, 305-326.

McGorry, P. D., Yung, A. R., Phillips, L. J., et al (2002) Randomized controlled trial of interventions designed to reduce the risk of progression to first-episode psychosis in a clinical sample with subthreshold symptoms. Archives of General Psychiatry, 59, 921-928.

Moscarelli, M., Capri, S. \& Neri, L. (1991) Cost evaluation of chronic schizophrenic patients during the

RICHARD WARNER, MB, DPM, Mental Health Center of Boulder County and University of Colorado; Mental Health Center of Boulder County, I333 Iris Avenue, Boulder, Colorado 80304, USA. Tel: +0I 303443 8500; fax: +0l 303449 6029; e-mail: drdickwarner@aol.com

first three years after the first contact. Schizophrenia Bulletin, 17, $421-426$

Mosher, L. R. (1995) The Soteria Project: The first generation American alternatives to psychiatric hospitalization. In Alternatives to Hospital for Acute Psychiatric Treatment (ed. R. Warner), pp. III-129. Washington, DC: American Psychiatric Press.

\section{Norman, R. M. G., Townsend, L. \& Malla, A. K.} (200I) Duration of untreated psychosis and cognitive functioning in first-episode patients. British Journal of Psychiatry, 179, 340-345.

Parry-Jones, W. L. (1972) The Trade in Lunacy: A Study of Private Madhouses in England in the Eighteenth and Nineteenth Centuries. London: Routledge \& Kegan Paul.

Scull, A. T. (1979) Museums of Madness: The Social Organization of Insanity in Nineteenth-Century England. New York: St Martin's Press.

Scully, P. J., Coakley, G., Kinsella, A., et al (1997) Psychopathology, executive (frontal) and general cognitive impairment in relation to duration of initially untreated versus subsequently treated psychosis in chronic schizophrenia. Psychological Medicine, 27, 1303-1310.

Tien, A.Y. \& Eaton, W. W. (1992) Psychopathologic precursors and sociodemographic risk factors for the schizophrenia syndrome. Archives of General Psychiatry, 49, 37-46.

Tsoi, W. F. \& Wong, K. E. (199I) A I5-year follow-up study of Chinese schizophrenic patients. Acta Psychiatrica Scandinavica, 84, 217-220.
Waddington, J. L., Youssef, H. A. \& Kinsella, A. (1995) Sequential cross-sectional and 10 -year prospective study of severe negative symptoms in relation to duration of initially untreated psychosis in chronic schizophrenia. Psychological Medicine, 25 849-857.

Warner, R. (2002) Limitations of the Bonn Scale for the Assessment of Basic Symptoms as a screening measure. Archives of General Psychiatry, 59, 470-47I.

Warner, R. (2004) Recovery from Schizophrenia: Psychiatry and Political Economy (3rd edn). Hove, UK: Brunner-Routledge.

Warner, R. \& De Girolamo, G. (1995) Epidemiology of Mental Disorders and Psychosocial Problems:

Schizophrenia. Geneva: World Health Organization.

World Health Organization (1979) Schizophrenia: An International Follow-up Study. Chichester, UK: Wiley.

Wyatt, R. J., Green, M. F. \& Tuma, A. H. (1997) Longterm morbidity associated with delayed treatment of first admission schizophrenic patients. Psychological Medicine, 27, 261-268.

Yung, A. R., Phillips, L. J., McGorry, P. D., et al (1998) Prediction of psychosis. A step towards indicated prevention of schizophrenia. British Journal of Psychiatry, 172 (suppl. 33), 14-20.

Yung, A., Philips, L., McGorry, P. D., et al (2002) Predicting psychosis: Prospective follow-up of a highrisk group. Acta Psychiatrica Scandinavica, 106 (suppl. 413), 27. 